\title{
1 Diapause in Ticks of the Medically Important Ixodes ricinus
}

\section{Species Complex}

3 Jeremy S. Gray ${ }^{a}$, Olaf Kahl ${ }^{b}$, Robert S. Lane ${ }^{c}$, Michael L. Levin ${ }^{d}$, Jean I. Tsao

$4{ }^{a}$ School of Biology and Environmental Science, University College Dublin, Ireland

5 btick-radar $\mathrm{GmbH}$, Berlin, Germany

$6{ }^{c}$ Department of Environmental Science, Policy and Management, University of

7 California, Berkeley, California, USA

8 'Medical Entomology Laboratory, Rickettsial Zoonoses Branch, DVBD, Centers

9 for Disease Control and Prevention, 1600 Clifton Road, MS G-13, Atlanta, GA

10 30333, USA

$11{ }^{\mathrm{e}}$ Depts. of Fisheries \& Wildlife and Large Animal Clinical Sciences

12 Michigan State University, USA

\section{Abstract}

15 Four members of the Ixodes ricinus species complex, I. pacificus, I. persulcatus,

16 I. ricinus and $I$. scapularis, have, between them, a worldwide distribution within

17 the northern hemisphere. They are responsible for the transmission of several

18 animal and human pathogens, including the causal agents of Lyme borreliosis,

19 tick-borne encephalitis, human granulocytic anaplasmosis and human

20 babesiosis. Despite the importance of these ticks as vectors, the knowledge and

21 understanding of the role that diapause plays in their complex life cycles are

22 confused and incomplete. In view of the continuing geographic spread of these

23 tick species, as well as the effects of climate change on vector-borne diseases, it

24 is timely to encourage research on diapause phenomena to improve

25 understanding of their biology and of pathogen transmission dynamics. In our

26 review we seek to clarify thinking on the topic and to address gaps in our

27 knowledge that require the attention of researchers. 


\section{Introduction}

30 The Ixodes ricinus complex of ticks (Acari: Ixodidae), which comprises at

31 least 15 species distributed globally, has become particularly well known

32 because four species, I. ricinus and I. persulcatus in Eurasia, I. scapularis in

33 eastern and midwestern North America, and I. pacificus in western North

34 America, transmit many pathogens of both medical and veterinary significance.

35 These include the causal agents of Lyme borreliosis, Borrelia burgdorferi sensu

36 lato, considered to be the commonest and most widely distributed vector-borne

37 disease of humans in the temperate northern hemisphere (Stanek et al., 2012).

38 These four tick species are closely related and occupy similar niches in

39 their respective ecosystems. They are three-host ticks having catholic feeding

40 habits, with the adults occurring on medium-sized and large animals such as

41 hedgehogs, hares, deer and domestic livestock and the immature stages mainly

42 parasitizing lizards, birds and small to medium-sized mammals, in addition to

43 large animals (Fig. 1). Since they readily attach to and feed on humans they are

44 significant bridging vectors of zoonotic agents. In the case of I. persulcatus, the

45 adult females are the main vectors, whereas in the other three species all

46 parasitic stages bite humans, particularly the nymphs. They are exophilic, so

47 unlike most Ixodes spp., which seek their hosts in burrows and nests, they

48 ambush passing hosts in the open. Both developing and host-seeking (questing)

49 ticks are very vulnerable to desiccation, and therefore require microclimates

50 where the relative humidity remains above $80 \%$ for prolonged periods (Gray, 
51 1998). The ticks can quest for several months, but must replenish their reserves

52 of water by frequent journeys from the surface vegetation down to the base,

53 where they obtain water from sub-saturated air by secreting hygroscopic fluid

54 produced by the salivary glands onto the external mouthparts and then re-

55 ingesting the water-enriched fluid (Kahl and Knülle, 1988b). The length of time a

56 tick might remain in this questing phase is determined by its host-finding

57 success, the extent of its energy reserves available for water replenishment and

58 local microclimatic conditions. Questing by individual ticks can persist for several

59 weeks or months in suitable habitat, and is stage-dependent with larvae questing

60 for the shortest periods and adults for the longest.

61

62 Patterns of host-seeking behaviour

63 In all four species, host-seeking behaviour is distinctly seasonal, which is a

64 major determinant of the relative risk of tick bite. The nature of this seasonality

65 not only varies among tick species and life stages, but also according to the

66 latitude in which they occur. In I. ricinus, the most studied species, peak questing

67 of adult and nymphal ticks usually occurs in spring and early summer in northern

68 and central Europe, followed by comparatively low-level activity in mid-summer,

69 though questing may persist throughout the summer in cool and humid

70 conditions, especially in relatively protected habitats. In many areas, a second,

71 usually lesser, peak of activity occurs in autumn. Larval ticks typically begin

72 questing slightly later than the adults and nymphs, appearing in large numbers in

73 early summer and reaching their highest activity peaks in mid-summer prior to 
74 the second adult and nymphal peaks (Gray, 1991). In parts of southern Europe

75 and the southeastern extremity of the tick's range in Iran, the autumn/early winter

76 peaks, especially of the adults, tend to predominate and questing may occur

77 throughout the winter (Yousfi-Monod and Aeschlimann, 1986; Estrada-Peña et

78 al., 2004; Vahedi-Noori et al., 2012; Dantas-Torres et al., 2013). Notably, some

79 historical questing records from southern Europe might have been compromised

80 by the recent identification of a new species, I. inopinatus (Estrada-Peña et al.,

81 2014), which hitherto was considered to be I. ricinus.

82 The seasonal activity of $I$. persulcatus varies significantly in different parts of

83 its geographical range. The main difference from that of $I$. ricinus is that a second

84 peak of adults in autumn, often seen in I. ricinus, is uncommon in I. persulcatus

85 (Balashov, 1972; Korenberg, 2000). Adult I. persulcatus have a clearly defined

86 spring-summer activity period with a single peak in May or early June. The first

87 active I. persulcatus adults appear in late March (Korenberg, 2000); the lower

88 threshold of their questing activity is approximately $1^{\circ} \mathrm{C}$ (Kheisin et al., 1955). In

89 most cases, adult activity ceases in July/early August, depending on the weather

90 conditions (Korenberg, 2000; Babenko, 1985a). However under the maritime

91 climate in the south of the Russian Far East, limited adult I. persulcatus activity

92 may persist into early November (Babenko, 1985a). Larvae capable of infesting

93 animal hosts usually emerge in May, but in the maritime regions this sometimes

94 occurs in late April (Babenko, 1985a). The earliest collections of unfed larvae by

95 flagging from vegetation have also been reported to be May (Babenko, 1985a;

96 Levin, 1987). Although each individual larva can survive for only a few days after 
97 becoming active, they can be collected from both hosts and vegetation until

98 September/October due to asynchronous activation (Babenko,1985a; Levin,

99 1987; Korenberg, 2000). The first seasonal peak of larval abundance occurs in

100 June, and the second smaller peak, when present, in late August or September.

101 The seasonal dynamics of nymphal I. persulcatus, assessed by flagging from

102 vegetation and by collecting from a wide range of vertebrate hosts, suggest that

103 nymphs are usually active from April/May until late summer, with the peak of

104 seasonal activity recorded in early or late summer depending on the climatic

105 conditions (Levin,1984; Babenko,1985b). In the Baltic region, a second peak may

106 be present in the autumn when nymphs of the new generation, moulting from

107 larvae fed in the spring, complete post-moulting development in the same

108 season. This second peak is always much smaller and shorter in duration than

109 the first one.

110 The seasonal activity of the Nearctic species, I. scapularis, differs in certain

111 respects from that of $I$. ricinus and varies both latitudinally and longitudinally. In

112 northeastern USA, the autumn adult peak tends to be larger than the spring

113 peak, with nymphal activity in spring and early summer, and larval activity in mid-

114 summer (Spielman et al., 1985). In the northcentral region, the relative sizes of

115 the autumn and spring peaks may be more comparable, and the nymphal and

116 larval activity overlap in late spring and early summer (Gatewood et al., 2009;

117 Hamer et al., 2012; Tsao, unpublished data). In southern areas, as in southern

118 Europe for $I$. ricinus, autumnal and winter tick activity is predominant for adults

119 (Harris,1959; Cilek et al., 2000; MacKay and Foil, 2005) with larvae and nymphs 
120 active throughout the spring and summer (Kollars et al.,1999; Clark et al.,1998;

121 Tsao, unpublished data).

122 In the other Nearctic species, I. pacificus, the activity of northern Californian

123 populations resembles that of northeastern populations of $I$. scapularis, with adult

124 activity from late autumn to early spring, nymphs peaking in mid-spring, and

125 larvae peaking in spring to early summer (Westrom et al., 1985; Lane, 1990;

126 Clover and Lane, 1995; Eisen et al., 2001; Salkeld et al., 2014). In southern

127 California, the temporal abundance and seasonality of $I$. pacificus adults in the

128 Santa Monica Mountains are similar to those reported for some northern

129 Californian populations (Lane et al., 2013). Limited sampling by dragging litter or

130 removal from lizards in the same general study area revealed that the nymphs

131 are active from early March to late May and the larvae in April and May.

132 MacDonald and Briggs (2016) reported that the seasonal activity periods of

133 immature stages are highly truncated in southern California compared to those in

134 the north of the state, and suggested that this brief window for horizontally

135 transmitted pathogens has important implications for pathogen transmission

136 dynamics. The situation in more northerly areas (Oregon, Washington, British

137 Columbia) is unclear because few systematic studies have been conducted, but

138 it seems likely that the adults are most active in spring and autumn, the nymphs

139 in spring and early summer, and the larvae in mid-summer (Arthur and Snow,

140 1968). Thus, superficially northern I. pacificus seasonal activity resembles that of

141 I. ricinus in central and northern Europe.

142 To summarize, these four closely related Ixodes species exhibit very similar 
143 biologies and seasonalities, despite occupying widely separated geographical

144 areas, spanning several degrees of latitude, and display similar patterns of host-

145 seeking seasonality, though these differ in some minor respects. Reported

146 differences could be caused by several factors, including intrinsic biological

147 differences and differences in habitats, but also lack of suitable comparative

148 data, so that in some cases any disparity may be more apparent than real. If the

149 underlying mechanisms determining seasonality could be clarified, a level of

150 predictability in risk should be attainable, which would inform practical preventive

151 measures against the tick-borne pathogens they transmit.

153 Explanations of seasonal activity patterns

154 Several theories have been advanced to explain patterns of seasonal

155 questing activity in I. ricinus-complex ticks. At one time it was suggested that the

156 timing of development and questing activity of I. ricinus was driven entirely by

157 temperature. Bimodal activity was explained as the result of two successive

158 broods in the same year (Milne, 1945). Such interpretations were based largely

159 on the assumption that activity peaks of different stages reflect successive

160 development, i.e. larva to nymph to adult. However, when the development of

161 engorged ticks was followed in the field in several geographical areas, it was

162 discovered that successive peaks are not necessarily related to each other and

163 that the life cycle is rarely completed in less than two years, usually three, and

164 may take as long as six (Babenko, 1956; Chmela, 1969; Bauch, 1972; Gray,

165 1982; Shashina, 1985; Kahl, 1989; Estrada-Peña et al., 2004; Korotkov, 2008). 
166 There is now general agreement that the mechanisms regulating I. ricinus

167 seasonal activity are determined by a biological strategy in which ticks avoid

168 questing at unfavourable times of the year, such as mid-summer when the

169 temperature is too high and humidity too low for survival, or winter when

170 temperatures are too low for efficient questing activity or for development of

171 engorged stages. There is no doubt that to a certain extent the tick maximizes

172 survival by responding to ambient conditions. Thus, MacLeod (1935) reported

173 that $I$. ricinus ceases questing when temperatures exceed $35^{\circ} \mathrm{C}$, ticks avoid direct

174 sunshine (Babenko, 1974; Kahl and Knülle, 1988a), and activity is correlated with

175 saturation deficit (Perret et al., 2000). Temperature, degree and amount of

176 sunshine, rainfall and relative humidity have been correlated either negatively or

177 positively with questing behaviour of Ixodes spp. in several studies (Zemskaya

178 1984; Goddard, 1992; Mejlon, 1997; Vail and Smith, 1998, Eisen et al., 2002;

179 Hubalek et al., 2003; Lane et al., 2007; Kiewra et al., 2014; Berger et al., 2014;

180 Daniel et al., 2015), but the importance of these factors vary in different habitats

181 and are mainly relevant in that they impact the water balance and energy

182 depletion of the tick, and thus its survival. Whereas responses to ambient

183 conditions can best be described as tactical, anticipation of unfavourable

184 conditions well in advance of predictable seasonal climate changes is more of a

185 strategic response, and the mechanisms involved are various forms of diapause

186 that are incorporated into the developmental biology of these tick species.

187 Diapause mechanisms therefore have a role in determining the fundamental

188 phenology of a tick species. Activity peaks of a particular stage may consist of 
189 individuals of different generational cohorts, so observations of the seasonal 190 occurrence of larvae, nymphs and adults on vegetation or hosts, as illustrated in

191 Fig. 2A, a hypothetical representation of seasonal activity within one year,

192 cannot determine their origin. The data required for such a determination can

193 only be acquired when the development of groups of ticks of each life stage,

194 deposited at intervals in the vegetation, is followed under quasi-natural

195 conditions. The origin of the peaks displayed in Fig. 2A, and the role of diapause

196 in regulating the timing of their appearance, are illustrated in Fig. 2B. Ticks

197 feeding before the critical photoperiod moult in the same year and overwinter as

198 unfed ticks, possibly in behavioural diapause; those feeding thereafter enter a

199 developmental diapause, overwinter in the engorged state, and moult only in the

200 summer of the following year. Note that Fig. 2 does not illustrate the life cycle of

201 I. ricinus, but is a hypothetical representation of how these two developmental

202 groups relate to each other in regions where significant autumn activity occurs. In

203 other parts of the distribution range of $I$. ricinus, where little autumn activity is

204 evident, I. ricinus behaves more like I. persulcatus, in which activity is postponed

205 until the following spring. The two developmental groups are flexible and some

206 interchange of individuals between them always occurs, depending on whether

207 ticks feed before or after the critical seasonal point of diapause induction. The life

208 cycle may therefore be significantly lengthened when ticks enter diapause or

209 shortened when they feed prior to this period.

210

\section{Nature of dormancy phenomena}


212 Dormancy in biology is generally regarded as a state of minimal metabolic

213 activity with cessation of growth and development, either as a reaction to adverse

214 conditions or as part of an organism's normal annual rhythm. Most authors

215 further subdivide the phenomenon by distinguishing between quiescence, a state

216 of torpidity, which is an immediate response to prevailing hazardous

217 environmental conditions, usually low temperatures, and diapause, a period of

218 hormonally-controlled arrested development. Diapause usually occurs seasonally

219 before environmental conditions become unfavourable, and has a fixed latency

220 period that must be completed before development can resume (Tauber et al.,

221 1986). In contrast, quiescence ceases with the disappearance of adverse

222 conditions. If, in some years, the length of the diapause period is insufficient to

223 avoid unfavourable conditions, the organism may enter a post-diapause

224 quiescence and will remain torpid until favourable conditions occur (Belozerov,

225 2009). Under field conditions it can be very difficult to determine precisely when

226 such a transition from diapause to quiescence has occurred.

227 The study of tick diapause is in its infancy compared with insect diapause,

228 but nevertheless there are many similarities between the two, including the use

229 of similar terminology. Since, in the view of some authorities published studies of

230 insect diapause contain many misstatements and misunderstandings (Kostal,

231 2006), it is hardly surprising that there is considerable confusion about tick

232 diapause. Few reviews of tick diapause have been published, the most complete

233 being those of Belozerov $(1982,2009)$ on both argasid and ixodid ticks, and

234 another more focused review restricted to the prostriate (Ixodes spp.) ticks and to 
235 one form of diapause only, developmental diapause (Belozerov et al., 2002).

236 Although providing much information, especially on environmental triggers of

237 diapause initiation/termination, these reviews do not appear to have resulted in

238 much clarity and understanding of how diapause phenomena regulate Ixodes

239 spp. life cycles in the field.

240 Most authors distinguish two main types of tick diapause - developmental

241 (morphogenetic), here including reproductive, and behavioural. Developmental

242 diapause describes a cessation of the development of engorged ticks at a

243 predictable time owing to the blocking of essential steps in the developmental

244 process, which presumably are under hormonal control (Belozerov, 1982). This

245 form of diapause may manifest either as delays in oviposition or in the

246 development of eggs, engorged larvae or engorged nymphs. Behavioural

247 diapause involves temporary suppression of host seeking and/or attachment by

248 unfed ticks (Belozerov, 1982). In some of the literature this term is loosely

249 applied to overwintering ticks that are not necessarily in true diapause, but may

250 be in a temperature-regulated quiescence. It is impossible to distinguish between

251 the two by simple observation under field conditions, especially with the added

252 complication of post-diapause quiescence. Behavioural diapause may best be

253 detected by attempting artificial stimulation of activity and feeding in individual

254 specimens, or by extrapolation from laboratory experiments.

255 Genuine behavioural diapause is a well-documented phenomenon in

256 metastriate ticks (Wilkinson, 1968; McEnroe, 1985; Addison et al., 1988; Pegram

257 and Banda, 1990; Fujimoto, 1995, 1998, 1999; Madder et al., 1999; Cabrera and 
258 Labruna, 2009), but is less well known in the prostriate ticks (Ixodes spp.).

259 Together, the two forms of diapause synchronize tick development and host-

260 seeking activity with the seasons, so that vulnerable ticks are less exposed to the

261 dangers of dehydration or freezing. In I. ricinus in central and northern Europe,

262 diapause also ensures that the nymphal and adult moults occur during the

263 warmest part of the year, which minimizes the length of the pharate phases and

264 maximizes the rate of metabolic water gain by the ticks (Kahl, 1991).

265 However, since both forms of diapause cause delays in the life cycle, they

266 tend to reduce reproductive fitness, and so are only brought into play when the

267 nature of the seasonal climate threatens tick survival (Randolph, 2013).

269 Induction, maintenance and termination of diapause in ticks

270 Diapause occurs after ticks are exposed to an induction stimulus (i.e., 271 conditioned), typically at a particular time of year. The primary stimulus for

272 diapause induction appears to be photoperiod, with temperature having an

273 important modifying influence in some cases. The threshold period or critical

274 diapause period (defined by a critical photoperiod), after which more than $50 \%$ of

275 ticks enter diapause, varies with latitude, life stage and probably the genetics of

276 the local tick population.

277 One of the seminal studies examining the role of photoperiod as a

278 regulating factor in ticks was undertaken in North America by Smith and Cole

279 (1941) working on the seasonal activity of Dermacentor variabilis. By the 1960s, 280 photoperiod had been implicated as a regulator of the metamorphosis of $I$. ricinus 
281 and I. persulcatus (Belozerov, 1964; Babenko and Platonova, 1965). Since then,

282 physiological responses to photoperiod have been found to be widespread in

283 ticks. In northern regions, a change from long to short days is necessary to

284 induce both behavioural and developmental diapause. Through perception of this

285 reliable environmental change, the ticks can anticipate the onset of winter,

286 ensuring that oviposition and moulting occur at favourable summer temperatures.

287 In some metastriate species, such as Rhipicephalus appendiculatus, a

288 behavioural diapause occurs as a result of prior exposure to long-day signals, 289 resulting in the avoidance of questing during mid-summer, the warmest time of

290 the year (Madder et al., 1999). There is no evidence in northern regions for such

291 a 'summer diapause' among the prostriate ticks (Ixodes spp.), which apparently

292 utilize tactical behavioural responses, such as retreating to cool humid

293 microclimates, to overcome the dehydration risks that are posed by mid-summer

294 temperatures and high saturation deficits. However, life cycle studies on I.

295 pacificus in northern California suggest that a behavioural diapause may occur in

296 immature ticks to enable them to survive the hot dry summers and become active

297 in late winter or early spring (Padgett and Lane, 2001). A similar situation may

298 occur in southern races of $I$. ricinus, for example in North Africa and southern

299 Italy, and in I. scapularis in southern USA.

300 The precise phases of the developmental cycle where ticks are sensitive to

301 diapause induction stimuli have received some attention, but this topic requires

302 further elucidation. According to Belozerov (1982), tick diapause is unlike

303 diapause in many insects in that sensitivity to photoperiod occurs in some 
304 developmental phases throughout the development cycle (pre-feeding, feeding,

305 post-feeding), but the precise nature of the response depends on the species

306 and population involved. In early laboratory experiments on I. persulcatus,

307 Babenko and Platonova (1965) demonstrated that in ticks of Far Eastern and

308 Siberian origin, development of engorged larvae depends on the photoperiodic

309 conditions both before and after feeding and moreover, the percentage of larvae

310 developing with or without a diapause was affected by both the direction of the

311 change and length of the period before the change (Babenko, 1969). For

312 example, fed larvae kept in a long photoperiod for up to 10 days after

313 engorgement and then transferred to a short photoperiod entered diapause,

314 while most of those kept under long-day conditions for 15-20 days post-

315 engorgement developed into nymphs without a delay, despite being transferred

316 to a short photoperiod subsequently. Ixodes ricinus reportedly shows similar

317 sensitivities to photoperiod in its larval and nymphal stages (Belozerov, 1964).

318 An informal survey of 18 laboratories in which one or more of the four

319 Ixodes spp. under consideration are reared under artificial conditions, provided

320 further evidence that ticks respond variably to diapause induction stimuli (Table

321 1). Nevertheless, a pattern emerges and it can be concluded that in these

322 laboratories diapauses are avoided by exposing ticks to a transition of short-day

323 to long-day photoperiods during one or more phases of development, and/or by

324 the provision of high temperatures $\left(21-24^{\circ} \mathrm{C}\right)$. It should be noted, however, that

325 high temperatures might eventually lead to reduced feeding rates and shortened

326 life-expectancy. It is also possible that prolonged storage under continuous dark 
327 or light conditions may compromise the tick's biological clock. Nevertheless,

328 storage of nymphs and adults at $4^{\circ} \mathrm{C}$ in the dark before feeding (i.e. simulating

329 winter) appears to benefit colonies by improving both feeding and moulting rates.

$330 \quad$ Few studies have specifically addressed the factors responsible for

331 terminating diapause in Ixodes spp. ticks, which may occur as a result of the

332 cessation of diapause maintenance stimuli, exposure to particular diapause

333 termination stimuli or even as an essentially spontaneous change over time from

334 a diapausing to a non-diapausing state. The most likely situation is that all three

335 models apply to some extent.

336 Belozerov (2009) lists several factors for the induction of developmental and

337 behavioural diapause in I. ricinus, I. persulcatus and I. scapularis, primarily rising

338 temperatures and increasing day-length, but how these interact with each other

339 is uncertain. Fujimoto (2003), concluded that behavioural diapause in I.

340 persulcatus could be terminated by exposure to a photoperiod of $12 \mathrm{~L}-12 \mathrm{D}$ for 7

341 months, following rearing and maintenance at $16 \mathrm{~L}-8 \mathrm{D}$ and $24^{\circ} \mathrm{C}$. However, this

342 very high temperature makes it difficult to relate the study to natural conditions.

343 The gradual increase in the abundance of active I. ricinus and I. persulcatus

344 in spring (Fig. 2) suggests that temperature changes, while not necessarily

345 responsible for terminating behavioural diapause, have a major role in

346 determining the readiness of the ticks to commence questing. Indeed, it is likely

347 that a post-diapause quiescence occurs immediately following the termination of

348 diapause, as discussed by Belozerov (2009), so that regardless of the role of

349 photoperiod, the appearance of questing ticks in the spring becomes primarily 
350 temperature-driven. It is also probable that the threshold for activity, whether

351 driven by temperature, photoperiod, or both, varies for individual ticks.

$352 \quad$ Little is known about the physiology of diapause in ticks, but Belozerov

353 (1982) suggested that, as in insects, there are three main steps in the processing

354 of seasonal information by ticks. Firstly, the perception of extrinsic signals such

355 as photoperiod (or scotoperiod), secondly the accumulation of this information in

356 the brain and thirdly the transformation of this information via neurosecretory

357 cells into hormonal signals that block or initiate metamorphosis. It has been

358 reported that the administration of ecdysone or juvenile hormone analogues can

359 terminate diapause in argasids (Bassal and Roshdy, 1974) and metastriate

360 ixodids (Sannasi and Subramoniam, 1972), but this model of the physiological

361 mechanisms responsible for tick diapause remains speculative until further data

362 on the topic can be obtained.

363 It is still uncertain whether tick diapause is induced by a physiological switch

364 activated when a certain day-length threshold is reached, or whether the tick

365 responds to a gradual change in day length. Most laboratory studies on tick

366 diapause appear to have been conducted on the assumption that a specific day

367 length by itself is enough to induce diapause (Belozerov, 1982). Although such

368 experimental designs resulted in observable diapause effects, accumulation of

369 sensory information due to gradual changes in day length may be more relevant

370 in nature and, ideally, should be incorporated into the design of future laboratory

371 experiments. 


\section{Intraspecific differences between populations}

374 It is intuitive that, given the extensive geographical distribution of the four

375 Ixodes spp. considered here, phenotypic differences would occur among

376 populations, including responsiveness to diapause-conditioning stimuli. Although

377 environmental conditions probably give rise to regional differences, genetically-

378 determined responses may also differ, as demonstrated for behavioural diapause

379 in Rhipicephalus appendiculatus (Madder et al., 1999). Studies on the population

380 genetics of the four tick species considered here are in their infancy, but the

381 identification of genetically distinct strains of ticks are necessary before

382 phenotypic differences can be considered in context.

383 Although no population genetic studies appear to have been undertaken on

384 I. persulcatus, there are interesting data on regional differences in diapause-

385 induction dates for I. persulcatus larvae and nymphs. According to Korotkov

386 (2009), these differences are due to adaptation of $I$. persulcatus populations to

387 regional climatic conditions. In the European part of the distribution range

388 (latitude $56^{\circ}-57^{\circ} \mathrm{N}$ ), the critical diapause period for engorged larvae occurs

389 between July 25 and August 2. In West Siberia (latitude $53-56^{\circ} \mathrm{N}$ ), with its harsh

390 continental climate, this date is between July 10 and July 29 , an average of 8

391 days earlier than in central Russia. Conversely, the average critical diapause

392 date for larval diapause in Far Eastern populations (latitude $43-49^{\circ} \mathrm{N}$ ) is delayed

393 until August 4-16, or by approximately 24 days, compared to the West Siberian

394 populations. These data suggest that in eastern Europe $50 \%$ of engorged larvae

395 enter diapause when the day length shortens to approximately 16.0-16.2 hours; 
396 in Western Siberia to 16.0-16.5 hours; and in Russian Far East to 14.0-14.5

397 hours. The critical diapause date for larvae occurs earlier as the distance from

398 the Pacific Ocean increases and the climate becomes harsher and more

399 continental. These variations in diapause-induction dates may be caused by

400 genetic adaptations of different populations of $I$. persulcatus to local conditions.

401 Similar, though limited, observations on I. ricinus were made by Belozerov

402 (1966a), who reported that the photoperiod reactions of northern (Leningrad,

$40359.6^{\circ} \mathrm{N}$ ) and southern (Moldavia, $46.3^{\circ} \mathrm{N}$ ) larval populations differed by a few

404 hours. Regional differences between other I. ricinus populations also occur, as

405 described by Estrada-Peña et al. (1996) for cuticular hydrocarbon variations, and

406 Gilbert et al. (2014) for questing temperatures of ticks from northeast Scotland

$407\left(56.5^{\circ} \mathrm{N}\right)$ compared with central France $\left(45.5^{\circ} \mathrm{N}\right)$.

408 Population genetic studies have been conducted on I. pacificus (Kain et al.

409 (1997) and I. scapularis (Qiu et al., 2002), and for both species it has been

410 observed that northern ticks tend to quest from surface vegetation, whereas

411 further south they quest beneath the vegetation (Lane et al., 2013; Arsnoe et al.,

412 2015). In the case of I. scapularis, this difference cannot be explained by

413 environmental conditions alone and probably has a genetic basis (Arsnoe et al.,

414 2015). These north-south regional differences suggest that the relative

415 susceptibility of tick populations to diapause-induction stimuli may also differ.

416

417 Diapause in Ixodes ricinus

$418 \quad$ There are more studies addressing diapause in I. ricinus than in any other 
419 tick species, mainly because of the large body of work by Belozerov (e.g., 1964;

420 1966a,b; 1967a,b; 1971; 1973), primarily involving ticks from the Leningrad/St.

421 Petersburg area in Russia. The laboratory experiments described in these

422 publications consisted of manipulating the photoperiod and/or temperature during

423 various phases of the tick life cycle, mainly the post-engorgement development

424 phase, but also before and during feeding. Unfortunately, these remain the only

425 laboratory-based studies of diapause phenomena in I. ricinus, and since they

426 have almost all appeared in the Russian literature, many important details are

427 difficult to access. Their complex design was apparently intended to address the

428 mechanisms of diapause, and Belozerov (1998) concluded from his experiments

429 that a two-step process occurred, involving separate responses to long- and

430 short-day photoperiods. Furthermore, ticks apparently remain sensitive to these

431 photoperiods throughout their life cycle including both questing and engorged

432 stages. Laboratory studies are undoubtedly very useful, but highly relevant data

433 can also be obtained from studies of tick development under natural conditions.

434 The deposition of tubes containing engorged specimens within the natural habitat

435 has furnished us with such data for I. ricinus (Campbell, 1948; Chmela, 1969;

436 Bauch, 1972; Gray, 1982; Kahl, 1989; Estrada-Peña et al., 2004) including in

437 some cases, the onset of activity (Gray, 1982). Additional indirect evidence for

438 the role and importance of diapause has been obtained from several modelling

439 studies of the I. ricinus life cycle, in which the best theoretical fit with the

440 observed data occurred when both developmental and behavioural diapauses

441 were built into the models (Gardiner and Gray, 1986; Walker, 2001; Dobson et 
442 al., 2011; Hancock et al., 2011).

444 Developmental diapause

445 The many laboratory studies on developmental diapause in Ixodes spp.

446 (summarized in Belozerov et al., 2002) clearly demonstrated its existence in $I$.

447 ricinus larvae and nymphs and there is some evidence that an egg diapause

448 occurs (Belozerov, 1973; Gray, 1982). However, a pre-ovipositional diapause,

449 which features in the life cycles of many metastriate ticks and some other Ixodes

450 spp. (see below), does not seem to occur in I. ricinus (Belozerov et al., 1966b;

451 1973; 1982; Gray, 1981; 1982).

452 Belozerov's experiments suggest that if larval and nymphal ticks are

453 exposed to increasing hours of light from the unfed phase through feeding and

454 into the post-engorgement phase, they will develop without any developmental

455 diapause. On the other hand, if exposed to decreasing hours of light in the

456 laboratory, diapause will ensue and development will not commence in the

457 engorged specimens for at least 90 days. The same phenomenon occurs in adult

458 ticks, but although the diapause-induction stimulus is perceived by the unfed

459 female, the developmental diapause manifests as delayed embryogenesis within

460 the eggs, rather than delayed oogenesis (Belozerov, 1973).

461 Although photoperiod is regarded as the primary environmental signal that

462 induces developmental diapause, tick age and ambient temperature have

463 important modifying effects. For example, it was found that the older the larvae

464 are at the time of feeding, the greater the proportion that enter developmental 
465 diapause (Belozerov, 1967a). In the same paper Belozerov reported that when

466 larvae were maintained under short-day conditions, which would be expected to

467 induce developmental diapause in the following post-engorgement phase,

468 temperatures above $25^{\circ} \mathrm{C}$ before feeding prevented subsequent diapause in

469 young larvae ( $<1$ month after hatching). High temperatures may also terminate

470 developmental diapause in larvae under laboratory conditions (Campbell, 1948).

471 Temperature effects (accelerated development of eggs and high temperature

472 termination of diapausing engorged larvae) were postulated to affect tick-

473 seasonal dynamics in Ireland for two years following the very hot year of 1976

474 (Gray, 1984; Gardiner and Gray, 1986). Interestingly, Dautel and Knülle (2009)

475 reported that in the laboratory, continuous cold temperatures such as $4^{\circ} \mathrm{C}$ for at

476 least 6 weeks, or -10 and $-20^{\circ} \mathrm{C}$ for $24 \mathrm{~h}$, completely eliminated egg diapause

477 which suggests that in regions that experience harsh winters, few larvae are

478 likely to join the diapausing part of the population, because they will probably

479 become active before the diapause threshold period in late summer.

481 Behavioural diapause

$482 \quad$ Nearly 70 years ago, it was noted that in Scotland, ticks that moult in late 483 summer from spring and early-summer feeding ticks, were reluctant to become 484 active and feed, a manifestation of behavioural diapause, and usually

485 overwintered as unfed stages before becoming active in the spring (Campbell, 486 1948). However, I. ricinus nymphs have been reported questing in mild weather 487 in winter months (Dautel et al., 2008) and some researchers view winter 
488 dormancy as merely a form of temperature-controlled quiescence. Such a 489 quiescence probably applies to those individuals that feed as larvae and nymphs 490 in the autumn of the previous year, overwinter as diapausing engorged stages, 491 moult in late summer and become active in early autumn, without entering a 492 behavioural diapause (Gray, 1982). Their numbers are usually small compared 493 with nymphs and adults that are active only in spring and early summer, but this 494 can depend on the relative density of hosts in spring compared with autumn 495 (Gray, 1984). However, in many parts of the I. ricinus distribution range, almost 496 no autumn activity occurs, despite the availability, by late summer, of moulted 497 nymphs and adults derived from the developmental diapause cohort. These ticks 498 are presumably in a form of behavioural diapause, but so far this has not been 499 investigated.

500 Despite the necessity for the inclusion of behavioural diapause in the 501 explanatory models of Walker (2001), Hancock et al. (2011) and Dobson et al. 502 (2011), few controlled experiments have been conducted to demonstrate its 503 existence. However, there is good evidence for behavioural diapause in nymphs 504 from a Russian (Leningrad/St. Petersburg) population (Belozerov, 1971). In that 505 study, recently moulted nymphs reared in a short-day regime were exposed to 506 long-day (20 hours light) or short-day (12 hours light) conditions and after several 507 months were tested for attachment rates on laboratory mice. It was found that 508 ticks maintained as unfed nymphs in long-day conditions fed 3-10 times more 509 readily than those maintained under short-day conditions. Switching ticks in 510 diapause from short-day to long-day regimens could terminate diapause and 
511 raising the temperature to $25^{\circ} \mathrm{C}$ could produce the same effect, demonstrating

512 the influence of an extrinsic factor other than photoperiod. However, if switched

513 from a long-day to a short-day regimen, the nymphs did not become less

514 aggressive, showing that once the ticks become active they cannot be induced to

515 enter behavioural diapause. This is in contrast to the metastriate tick,

516 Dermacentor marginatus, in which repeated induction of behavioural diapause in

517 unfed adults is possible (Belozerov, 1967b). A less strongly developed

518 behavioural diapause was demonstrated in nymphs in Ireland (Gray,

519 unpublished) where unfed nymphs maintained at $4^{\circ} \mathrm{C}$ in the dark for three

520 months (i.e. overwintered), all became active, when exposed to long-day

521 conditions compared with less than two-thirds of the nymphs maintained

522 previously at room temperature in long-day conditions (i.e., not overwintered).

523 These latter nymphs had attachment rates of only $27 \%$ on gerbils compared with

$52465 \%$ for the 'overwintered' group.

525 The only relevant published study on adults was incidental to an

526 investigation into the effects of off-host mating on questing activity (Gray, 1987).

527 Two groups of laboratory-reared unfed females, mated and unmated, were

528 tested for activity in vertical tubes placed in the natural habitat in early autumn,

529 following maintenance at room temperature and a long-day photoperiod. These

530 conditions were designed to simulate a cohort that had fed in the spring and

531 moulted in late summer and were therefore expected to exhibit behavioural

532 diapause. The majority (63\%) of the unmated ticks remained inactive,

533 demonstrating the expected behavioural diapause, albeit at a modest rate. 
534 However, all the mated females became active, suggesting that behavioural

535 diapause can be eliminated by a change in tick physiological condition.

536 It is uncertain whether a true behavioural diapause occurs in I. ricinus

537 larvae. Belozerov (1966a) maintained that there is no evidence for a photoperiod-

538 regulated behavioural diapause, though this is contradicted in tables published

539 later (Belozerov, 1982, 2009). However, no experimental evidence appears to

540 have been published. The lack of larval activity in late autumn and early winter

541 may be mainly due to the onset of low temperatures combined with the need for

542 recently hatched larvae to consume the residual lipids from the egg before

543 becoming active. In spring, the slight delay in larval activity relative to nymphs

544 and adults in Ireland (Gray, 1982) and the UK (Randolph et al., 2002) is thought

545 to result from the larval requirement for slightly higher approximate threshold

546 temperatures for the commencement of activity $\left(10^{\circ} \mathrm{C}\right)$ compared with nymphs

547 and adults $\left(7^{\circ} \mathrm{C}\right)$ (Randolph, 2004).

548 To summarise, there is strong evidence for developmental and behavioural

549 diapauses in $I$. ricinus, the former affecting eggs, larvae and nymphs, and the

550 latter nymphs and adults. Both forms of diapause are induced when ticks are

551 exposed to decreasing day length. Thus, engorged immature ticks overwinter

552 without further development until early summer, and ticks that moult in the

553 second half of the year, when days are shortening, are relatively reluctant to

554 quest and feed before winter, though some individuals are evidently capable of

555 becoming active. Studies on behavioural diapause are scarce and this topic

556 needs further investigation, particularly in an experimental laboratory setting. 
557 Both forms of diapause can be influenced by elevated temperatures, but more

558 data on this interaction are also required.

559

\section{Diapause in Ixodes persulcatus}

561 Developmental Diapause

562 Systematic studies on diapause in this tick species began with the work of

563 Babenko (1956) and was followed by many laboratory- and field-based

564 experiments on ticks from different parts of the geographical range. Much

565 information regarding the dynamics of development of engorged ticks under

566 natural conditions and the ability of different life stages to survive through the

567 winter has been generated by depositing ticks in containers in various tick

568 habitats (Babenko and Rubina, 1968; Babenko, 1985b; Korotkov and Kislenko,

569 1991). This approach established that an overwinter delay in development of

570 engorged larvae and nymphs is typical for $I$. persulcatus throughout its range

571 (Kheisin et al., 1955; Babenko, 1956; Babenko and Rubina, 1968; Zhmaeva,

572 1969). Moulting was still delayed for several months when late-engorged

573 immature ticks were exposed to temperatures as high as $16-23^{\circ} \mathrm{C}$ in the

574 laboratory (Kheisin et al., 1955).

575 Laboratory experiments on I. persulcatus larvae demonstrated that the

576 development of engorged larvae depends on the photoperiodic conditions of their

577 maintenance. All larvae held under a long photophase ( $\geq 18$ hours) both before

578 and after feeding moulted to nymphs without a diapause. Conversely, when

579 exposed to a short photophase (6 hours), $95 \%$ larvae showed delayed 
580 development (Babenko and Platonova, 1965). Similarly, I. persulcatus nymphs

581 also developed without diapause under long-day conditions, but showed a

582 developmental diapause when exposed to a short-day photoperiod during and

583 after engorgement (Fujimoto, 1993; Belozerov, 1995).

$584 \quad$ Neither engorged females nor eggs of $I$. persulcatus are capable of a

585 diapause, and all invariably die during the winter (Babenko and Rubina, 1968;

586 Kachanko, 1978). Therefore, engorged females must oviposit early enough for

587 the eggs to hatch within the same season. This notable difference from I. ricinus

588 is interpreted as an adaptation of $I$. persulcatus to harsher climatic conditions and

589 shorter warm seasons in the taiga region (Belozerov, 1981).

590

591 Behavioural diapause

592 In Russia, behavioural diapause in I. persulcatus prevents most adult and 593 nymphal ticks from feeding in late autumn (as observed for some populations of

594 I. ricinus - see above), so that they do not become active until the following

595 spring (Belozerov, 1985). Similar observations were made in a Japanese

596 population of $I$. persulcatus in which it was confirmed that behavioural diapause

597 is triggered by a transition from long-day to short-day photoperiods in both

598 nymphs (Fujimoto, 2002) and adults (Fujimoto, 2001, 2003). This overwintering

599 of unfed adults in behavioural diapause correlates with the inability of either

600 engorged females or eggs to undergo developmental diapause.

601 The existence of behavioural diapause in I. persulcatus larvae is

602 debatable. Larval behavioural diapause is referred to by Belozerov (1985), but 
603 experimental evidence is lacking, and behavioural diapause is not listed in a 604 table presented by Belozerov (1982), but is listed in Belozerov (2009). The 605 absence of larval activity in late autumn and early winter may be explained by the 606 onset of low temperatures, as in I. ricinus, but experimental investigations are 607 required.

608 I. persulcatus behavioural diapause in adults is probably obligatory under 609 natural conditions (Belozerov, 1985) and may be more strongly developed than 610 in I. ricinus (Balashov, 1972). Not only do adults that have fed as nymphs in the 611 spring and summer of the same year enter a behavioural diapause, but so do

612 those that overwintered in diapause as engorged nymphs the previous winter. In 613 contrast, in Ireland most I. ricinus adults developed from such nymphs start 614 questing within two or three weeks of moulting in the autumn (Gray, 1982). The 615 well-developed behavioural diapauses of nymphal and adult $I$. persulcatus 616 appear to be adaptations to the harsh winters characteristic of the geographical 617 range of this tick species.

618

619 Diapause in Ixodes scapularis

620 The first authors to refer to diapause in I. scapularis (then known as $I$.

621 dammini) were Yuval and Spielman (1990). They placed engorged stages

622 collected from mice (Peromyscus leucopus) or deer (Odocoileus virginianus) in

623 nylon mesh tubes that were partially buried in litter, and then made observations

624 on development times and mortality. They suggested that a developmental 625 diapause occurred in nymphs fed in August or later in the season and in larvae 
626 fed in September or later, and that a pre-ovipositional diapause occurred in

627 adults that fed during the autumn and which did not start laying eggs until June of

628 the following year. A behavioural diapause in nymphs was reported to extend

629 from their moult in summer to May of the following year, and adults that moulted

630 from nymphs in June/July apparently exhibited a short behavioural diapause until

631 September of the same year. According to these studies, therefore, I. scapularis

632 in Massachusetts differs from I. ricinus in Europe in that it shows no egg

633 diapause, but unlike I. ricinus undergoes a pre-oviposition diapause, which

634 seemed to be confirmed in similar field studies by Daniels et al. (1996) in New

635 York State. Pre-ovipositional diapause is also evident further north in Ontario,

636 Canada, according to the observations of Lindsay et al. (1998). Additionally, their

637 data suggest larval and nymphal developmental diapauses, a nymphal

638 behavioural diapause and possibly an egg diapause, not previously observed in

639 I. scapularis. The observed behavioural diapause of $I$. scapularis nymphs seems

640 to resemble that of $I$. ricinus, but the very short behavioural diapause in adults

641 reported by Yuval and Spielman (1990) (if it is indeed a classic diapause) does

642 not prevent questing in the autumn of the year that they moulted - unlike $I$.

643 persulcatus and to some extent, I. ricinus.

644 Some of these field observations may be explicable by responses to

645 ambient temperatures rather than diapause phenomena. However, Kahl (1989)

646 observed developmental diapause in larvae and nymphs of $I$. scapularis (I.

647 dammini) from Massachusetts, USA, at $90 \% \mathrm{RH}$ and 15 and $20^{\circ} \mathrm{C}$ in the

648 laboratory, and Belozerov and Naumov (2002) reported developmental diapause 
649 in I. scapularis nymphs in laboratory studies of a mid-Atlantic population. They

650 concluded that, as in I. ricinus, a two-step response to first long-day and then

651 short-day conditions were required. According to Yuval and Spielman (1990), the

652 importance of nymphal I. scapularis developmental diapause in nature is

653 questionable because the overwintering survival of diapausing individuals was

654 very poor and pre-empted by behavioural diapause in the nymphs. Nevertheless,

655 Ogden et al. $(2004,2005)$, who constructed a temperature-based development

656 model using laboratory data and also field data from Ontario, concluded that

657 development of engorged I. scapularis nymphs to adults is regulated to a

658 considerable extent by temperature-independent diapause phenomena.

659 It is evident that similar controlled laboratory studies to those of Belozerov

660 and Naumov (2002), as well as further field studies, are necessary to confirm the

661 existence and importance of developmental and other diapause phenomena in

662 this tick species.

663

664 Diapause in Ixodes pacificus

665 Ixodes pacificus is distributed over a considerable range of latitudes, 666 extending along the west coast of North America from Baja California north to

667 British Columbia; disjunct populations have been detected in Oregon, Nevada,

668 Utah and Arizona (.and Lane, 1996; Kain et al., 1997). Photoperiod and climate

669 might therefore be expected to significantly impact its life cycle, though the

670 biology of this tick has been poorly studied except in California (Furman and

671 Loomis, 1984; Peavey and Lane, 1996; Padgett and Lane, 2001). Peavey and 
672 Lane (1996) constructed a degree-day model for oviposition and hatching based

673 on data obtained from temperature regimes in the laboratory, and then compared

674 predicted development times with those observed during field observations of

675 confined engorged females placed within suitable habitat in northern California.

676 The model predicted the onset of oviposition accurately, but not that of hatching,

677 which occurred approximately a month later than predicted. These observations

678 suggest an absence of a pre-oviposition diapause, and the existence of an egg

679 diapause, though this was manifest as only a one-month delay in hatching.

680 However, the authors suggested that either inherent limitations of the model or

681 the influence of low humidity on egg development were the probable causes of

682 the discrepancies in egg hatch. They drew attention to the possible influence of

683 photoperiod, but this variable was not built into the experimental design.

684 In a similar study in northern California, Padgett and Lane (2001) fed all

685 stages of both colony and wild-caught ticks on rabbits (adults) or western fence

686 lizards (larvae and nymphs), and then deposited the engorged stages within silk

687 packets in the habitat at times of the year that corresponded with observed tick

688 feeding in nature. No pre-oviposition or developmental diapauses were observed,

689 but larvae and nymphs appeared to exhibit a distinct behavioural diapause. The

690 absence of developmental diapauses presumably reflects the fact that

691 overwintering of developing stages in this region is not particularly hazardous

692 because temperatures are high enough to permit development. The behavioural

693 diapauses in larvae and nymphs are a summer-survival strategy since they

694 prevent unfed ticks from questing during the hottest and driest time of year. 
695 Although mentioned in both papers considered here, photoperiod was not 696 investigated as a possible diapause-inducing factor in either study and, clearly,

697 the effects of photoperiod on tick development and activity under controlled 698 conditions are required to separate genuine diapause mechanisms from tick 699 responses to ambient conditions.

700

701 Comparison of diapause manifestations in I. ricinus, I. persulcatus, $I$. 702 scapularis and I. pacificus

703 The occurrence in the four Ixodes spp. of developmental and behavioural 704 diapauses supported by experimental data, is summarized in Table 2.

705 Developmental diapause in I. ricinus, I. persulcatus and I. scapularis is a 706 mechanism that enhances overwintering survival. In the two Palaearctic species, 707 I. ricinus and $I$. persulcatus, developmental diapauses are evident in engorged 708 larvae and nymphs. An egg diapause occurs in I. ricinus, but not in I. persulcatus. 709 In I. scapularis, a Nearctic species, no egg diapause has been reported, but a 710 pre-ovipositional diapause occurs. Although nymphal developmental diapause in 711 the field was reported in I. scapularis by Yuval and Spielman (1990), they 712 concluded that it may be of limited significance because of poor survival of 713 diapausing engorged individuals, an interpretation that is apparently at odds with 714 the observations of Kahl (1989) and Belozerov and Naumov (2002) that good 715 survival occurred under laboratory conditions.

716 In the other Nearctic species under consideration, I. pacificus, the most 717 complete studies have been conducted in northern California, where summer 
718 rather than winter is the major seasonal obstacle to completion of the life cycle.

719 Developmental diapauses were not observed in this tick, which evidently uses

720 behavioural diapause in the larval and nymphal stages to survive hot, dry

721 summer conditions. No diapause studies have been conducted in more northerly

722 populations of $I$. pacificus, so developmental diapauses may await discovery in

723 this species. Similarly, southern populations of I. ricinus and I. scapularis

724 exposed to very mild winters and hot summers have not been investigated for

725 behavioural diapauses that may help unfed stages to survive the summer.

$726 \quad$ Behavioural diapause has been reported in all four Ixodes spp. In I.

727 pacificus, it is an adaptation for summer survival, whereas in the other three

728 species it is evidently an overwintering mechanism. The phenomenon is strongly

729 developed in I. persulcatus; both nymphs and adults enter a behavioural

730 diapause in late summer or early autumn that prevents them from becoming

731 active until the following spring. The same is true for $I$. scapularis nymphs, which

732 in northern regions typically commence activity in autumn, become inactive in

733 winter and resume activity in spring. The situation in I. ricinus is both more

734 complex and more confused. Distinct behavioural diapause of a varying

735 proportion of individuals has been reported in both nymphs and adults, but some

736 studies have reported its absence and have interpreted low activity levels in late

737 autumn and winter as being due only to quiescence in response to low ambient

738 temperatures. There are contradictory reports on larval behavioural diapause in $I$.

739 ricinus and I. persulcatus. Although reported in both species (Belozerov, 2009),

740 detailed published experimental data seem to be lacking. 


\section{Conclusions and future research}

743 Diapause is evidently a widespread phenomenon in the life cycles of the

744 tick species considered here. Clearly, it has an important role in determining their

745 seasonal activity, and the consequent risk of infection and pathogen

746 maintenance within tick populations. An understanding of the precise role that

747 diapause plays in the life cycle of each species is particularly important in the

748 context of global climate change which may affect the timing of critical diapause

749 periods, thus influencing the activity, survival/longevity, and relative abundance

750 of questing ticks (Gray, 2008). Intraspecific differences in responses to diapause

751 induction and termination stimuli almost certainly exist, but have so far received

752 little attention.

$753 \quad$ Although the four species are closely related and occupy similar niches in

754 their respective ecosystems, there are marked differences among them in the

755 occurrence and expression of both developmental and behavioural diapause.

756 While such differences may provide insight into their life cycles, some may be

757 more apparent than real because of the difficulty of genuine comparisons.

758 Studies have been conducted in different geographical regions, often in widely

759 differing latitudes with different seasonal climate characteristics, and the methods

760 utilized have differed considerably. For example, some conclusions were based

761 solely on controlled laboratory studies, lacking natural context and with ticks from

762 just one geographical area, whereas others were based on field studies

763 conducted under quasi-natural conditions. In the latter case, it can be difficult to 
764 distinguish diapause phenomena from responses of the ticks to ambient

765 conditions. A combination of the two approaches seems best, but unfortunately

766 substantial data are only available for I. ricinus, and even in this species there

767 remain many unanswered questions.

768 There is a good case for researching all aspects of diapause in all four

769 species of ticks considered here, but the most pressing diapause questions to be

770 addressed are as follows:

771 I. ricinus

772 - Controlled laboratory studies on behavioural diapause of all three active

773 stages involving variable photoperiods and temperatures.

774 - Quasi-natural studies involving observation of development and questing

775 of confined ticks, especially in southern regions of its range.

776 I. persulcatus

777 - Controlled laboratory studies on behavioural diapause of all three active $778 \quad$ stages involving variable photoperiods and temperatures.

779 - Determination of presence or absence of egg diapause.

780 I. scapularis

781 - Controlled laboratory studies on behavioural diapause of all three active $782 \quad$ stages involving variable photoperiods and temperatures.

783 - Controlled laboratory studies on developmental diapause of engorged $784 \quad$ larvae and eggs.

785 - Quasi-natural studies involving observation of development and questing 786 of confined ticks in different geographical areas, particularly in southern 

regions of its range.

788

789

790

791

792

793

$794 \quad$ All species

795

796

797

798

800

801

802

803

804

805

806

807

808

809

I. pacificus

- Controlled laboratory studies on behavioural and possible developmental diapause of all three active stages involving variable photoperiods and temperatures.

- Quasi-natural studies involving observation of development and questing of confined ticks in northern regions of its range.

- Laboratory investigations on the interaction between temperature and photoperiod in inducing and terminating diapause.

- Tick-plot studies consisting of observations on activity of unconfined ticks deposited as engorged stages in small plots within the natural habitat (Dautel et al., 2008).

- Comparisons under controlled conditions of genetic susceptibility to diapause of geographically distinct populations of each species, including transplant studies of different genetic types. 
811 We are very grateful to the colleagues in 18 laboratories, who supplied

812 information on their tick-rearing methods for use in Table 1. Thanks are also due

813 to Bernard Kaye (University College Dublin) for his excellent work on the figures.

814 JIT acknowledges Funding provided by the National Science Foundation

815 (Emerging Infectious Disease Award EF-0914476).

816

817

818

819

820 Addison, E.M., McLaughlin, R.F., 1988. Growth and development of winter tick, 821 Dermacentor albipictus, on moose, Alces alces. J. Parasitol. 74, 670-678.

822 Arsnoe, I.M., Hickling, G.J., Ginsberg, H.S., McElreath, R., Tsao, J.I., 2015.

823 Different populations of blacklegged tick nymphs exhibit differences in

824 questing behavior that have implications for human Lyme disease risk. PLoS

825 One. 10(5):e0127450.

826 Arthur, D.R., Snow, K.R., 1968. Ixodes pacificus Cooley and Kohls, 1943: its life827 history and occurrence. Parasitology 58, 893-906.

828 Babenko, L.V., 1956. [Problem of seasonal variations and life of Ixodes ricinus L.

829 and Ixodes persulcatus P. Sch.] (Russian). Med. Parazitol. Parazit. Bolezn.

$830 \quad 25,346-352$.

831 Babenko, L.V., 1969. Diapause in larvae of Ixodes persulcatus (Parasitiformes:

832 Ixodidae) effect of some biotic and non-biotic factors on tick development. 
833 Proceedings of the $2 d$ International Congress of Acarology. Budapest; 447$834 \quad 453$.

835 Babenko, L.V., 1974. Diurnal variations in the activity of unfed nymphs, Ixodes 836 ricinus and I. persulcatus. (Russian). Med. Parazitol. Parazit. Bolezn. 43, $837 \quad 520-527$.

838 Babenko, L.V., 1985a. [Seasonal dynamics of activity.] (Russian). In: Filippova, 839 N.A. (Ed.), Taiga Tick Ixodes persulcatus Schulze (Acarina, Ixodidae):

840 Morphology, Systematics, Ecology, and Medical Significance. Nauka, 841 Leningrad, pp. 220-230.

842 Babenko, L.V., 1985b. [Duration of development of engorged larvae and 843 nymphs.] (Russian). In: Filippova, N.A. (Ed.), Taiga Tick Ixodes persulcatus 844 Schulze (Acarina, Ixodidae): Morphology, Systematics, Ecology, and Medical 845 Significance. Nauka, Leningrad, pp. 265-273.

846 Babenko, L.V., Platonova, V.F., 1965. [On diapause of larvae of Ixodes ricinus L.

847 and Ixodes persulcatus P. Sch. (Parasitiformes, Ixodidae). 1. Experimental 848 data on the effect of the photoperiod on hungry and fed larvae] (Russian). 849 Med. Parazitol. Parazit. Bolezn. 34, 69-73.

850 Babenko, L.V., Rubina, M.A., 1968. [Patterns of development of the taiga tick in 851 the vicinity of Kremenchug station] (Russian). In: Pospelova-Shtrom, M.V., 852 Rashina, M.G. (Eds.), Problems of Epidemiology of Tick-Borne Encephalitis 853 and Biological Patterns in its Natural Focus. Meditsina, Moscow, pp. 138$854 \quad 168$.

855 Balashov, Y.S., 1972. Blood Sucking Ticks (Ixodoidea), Vectors of diseases of 
856 man and animals. Medical Zoology Department USNMR Unit 3, Cairo, Egypt.

857 Bassal, T.T., Roshdy, M.A., 1974. Argas (Persicargas) arboreus: juvenile

858 hormone analog termination of diapause and oviposition control. Exp.

859 Parasitol. 36, 34-39.

860 Bauch, R.J., 1972. [Bionomy of Ixodes ricinus. II. Population and seasonal

861 dynamics in several localities of the district of Magdeburg in the GDR]

862 (German). Angew. Parasitol. 13, 141-154.

863 Belozerov, V.N., 1964. Larval diapause of the tick Ixodes ricinus L. and its 864 dependence on external conditions. Zool. Zhurn. 43, 1626-1637.

865 Belozerov, V.N., 1966a. Photoperiodic regulation of development and behavior of 866 Ixodes ricinus L. larvae and nymphs from different populations and its 867 changes owing to age of the ticks. Tezisy Dokl. 1. Akarol. Soveshch., pp. 2686827.

869 Belozerov, V.N., Bogdanov, V.E., Kvitko, N.V., 1966b. Seasonal changes in 870 temperature reaction of engorged Ixodes ricinus L. (Ixodidae) females. Vest. 871 Leningr. Univ., s. Biol. 3, 37-44.

872 Belozerov, V.N., 1967a. Larval diapause in the tick Ixodes ricinus L. and its 873 relation to external conditions. IV. Interactions between exogenous and 874 endogenous factors in the control of the larval diapause. Entomol. Rev. 46, $875 \quad 447-451$.

876 Belozerov, V.N., 1967b. Dependence of aggressiveness in adult Dermacentor 877 marginatus upon photoperiodic conditions. Parazitologiia Leningrad 9, 13-18. 878 Belozerov, V.N., 1971. Nymphal diapause in the tick Ixodes ricinus. IV. Influence 
879 of changes in photoperiodic regime of unfed nymphs on their aggressiveness.

$880 \quad$ Parazitologiia 5, 3-6.

881 Belozerov, V.N., 1973. [Egg diapause in Ixodes ricinus and its relation to the 882 photoperiodic conditions of maintenance of unfed females] (Russian). Vest.

883 Leningr. skogos Univ. Biol. 9, 33-37.

884 Belozerov, V.N., 1981. [Ecological rhythms in ixodid ticks and their regulation] 885 (Russian). Parazitol. Sb. (Leningrad). 30, 22-46.

886 Belozerov, V.N., 1982. Diapause and biological rhythms in ticks. In: Obenchain,

887 F.D., Galun, R. (Eds.), Physiology of Ticks, Pergamon Press, Oxford, pp. $888 \quad 469-500$.

889 Belozerov, V.N., 1985. [Diapause, its role in the life cycle, mechanism] (Russian).

890 In: Filippova, N.A. (Ed.), Taiga Tick Ixodes persulcatus Schulze (Acarina, 891 Ixodidae): Morphology, Systematics, Ecology, and Medical Significance.

$892 \quad$ Nauka, Leningrad, pp. 214-219.

893 Belozerov, V.N., 1995. [The photoperiodic regulation of the development and 894 diapause of the nymphs of the taiga tick Ixodes persulcatus (Ixodidae)] 895 (Russian). Parazitologiya 29, 101-104.

896 Belozerov, V.N. 1998. Participation of two-step photoperiodic reaction in control 897 of development and diapause in nymphs of Ixodes persulcatus. Zool. Zh. 77, $898 \quad 885-890$.

899 Belozerov, V.N., 2009. Diapause and quiescence as two main kinds of dormancy 900 and their significance in life cycles of mites and ticks (Chelicerata: Arachnida: 901 Acari). Part 2. Parasitiformes. Acarina 17, 3-32. 
902 Belozerov, V.N., Fourie, L.J., Kok, D.J., 2002. Photoperiodic control of

903 developmental diapause in nymphs of prostriate ixodid ticks (Acari: Ixodidae).

$904 \quad$ Exp. Appl. Acarol. 28, 163-168.

905 Belozerov, V.N., Naumov, R.L., 2002. Nymphal diapause and its photoperiodic

906 control in the tick Ixodes scapularis (Acari: Ixodidae). Folia Parasitol. (Praha)

$907 \quad 49,314-318$.

908 Berger, K.A., Ginsberg, H.S., Gonzalez, L., Mather, T.N., 2014. Relative humidity

909 and activity patterns of Ixodes scapularis (Acari: Ixodidae). J. Med. Entomol.

$910 \quad 51,769-776$.

911 Cabrera, R.R., Labruna, M.L., 2009. Influence of photoperiod and temperature on

912 the larval behavioral diapause of Amblyomma cajennense (Acari: Ixodidae).

913 J. Med. Entomol. 46, 1303-1309.

914 Campbell, J.A., 1948. The life history and development of the sheep tick Ixodes

915 ricinus L. in Scotland under natural and controlled conditions. Ph.D. Thesis,

$916 \quad$ University of Edinburgh (UK).

917 Chmela, J., 1969. On the developmental cycle of the common tick (Ixodes ricinus

918 L.) in the North Moravian natural focus of tick-borne encephalitis. Folia

919 Parasitol. (Praha) 16, 313-319.

920 Cilek, J.E., Olson, M.A., 2000. Seasonal distribution and abundance of ticks

921 (Acari: Ixodidae) in northwestern Florida. J. Med. Entomol. 37, 439-444.

922 Clark, K.L., Oliver, J.H., McKechnie, D.B., Williams, D.C., 1998. Distribution,

923 abundance, and seasonal activities of ticks collected from rodents and

924 vegetation in South Carolina. J. Vector Ecol. 23, 89-105. 
925 Clover, J.R., Lane, R.S., 1995. Evidence implicating nymphal Ixodes pacificus

926 (Acari: Ixodidae) in the epidemiology of Lyme disease in California. Am. J.

927 Trop. Med. Hyg. 53, 237-240.

928 Daniel, M., Malý, M., Danielová, V., Kř́ž, B., Nuttall, P., 2015. Abiotic predictors

929 and annual seasonal dynamics of Ixodes ricinus, the major disease vector of

930 Central Europe. Parasit. Vectors. 18;8:478. doi: 10.1186/s13071-015-1092-y.

931 Daniels, T.J., Falco, R.C., Curran, K.L., Fish, D., 1996. Timing of Ixodes

932 scapularis (Acari: Ixodidae) oviposition and larval activity in southern New

933 York. J. Med. Entomol. 33, 140-147.

934 Dantas-Torres, F., Otranto, D., 2013. Seasonal dynamics of Ixodes ricinus on

935 ground level and higher vegetation in a preserved wooded area in southern

$936 \quad$ Europe. Vet. Parasitol. 192, 253-258.

937 Dautel, H., Dippel, C., Kämmer, D., Werkhausen, A., Kahl, O., 2008. Winter

938 activity of Ixodes ricinus in a Berlin forest. Int. J. Med. Microbiol. 298,

939 supplement 1: 50-54.

940 Dobson, A.D.M., Finnie, T.J.R., Randolph, S.E., 2011. A modified matrix model

941 to describe the seasonal population ecology of the European tick, Ixodes

942 ricinus. J. Appl. Ecol. 48, 1017-1028.

943 Eisen, L., Eisen, R.J., Lane, R.S., 2002. Seasonal activity patterns of Ixodes

944 pacificus nymphs in relation to climatic conditions. Med. Vet. Entomol. 16, $945 \quad 235-244$.

946 Eisen, R.J., Eisen, L., Lane, R.S., 2001. Prevalence and abundance of Ixodes

947 pacificus immatures (Acari: Ixodidae) infesting western fence lizards 
948 (Sceloporus occidentalis) in northern California: temporal trends and

949 environmental correlates. J. Parasitol. 87, 1301-1307.

950 Estrada-Peña, A., Gray, J.S., Kahl, O., 1996. Variability in cuticular hydrocarbons

951 and phenotypic discrimination of Ixodes ricinus populations (Acarina:

952 Ixodidae) from Europe. Exp. Appl. Acarol. 20, 457-467.

953 Estrada-Peña, A., Martinez, J.M., Sanchez Acedo, C., Quilez, J., Del Cacho, E.,

9542004 . Phenology of the tick, Ixodes ricinus, in its southern distribution range

955 (central Spain). Med. Vet. Entomol. 18, 387-397.

956 Estrada-Peña, A, Nava, S, Petney, T., 2014. Description of all the stages of

957 Ixodes inopinatus n. sp. (Acari: Ixodidae). Ticks Tick Borne Dis. 5, 734-743.

958 Fujimoto, K., 1993. Effect of photoperiod on the attachment and development of

959 immature Ixodes persulcatus Schulze. Jpn. J. Sanit. Zool. 44, 271-277.

960 Fujimoto, K., 1995. Effect of photoperiod on the host attachment and

961 development in the tick, Haemaphysalis longicornis. Jpn. J. Sanit. Zool. 46,

$962 \quad 345-348$.

963 Fujimoto, K., 1998. Effects of photoperiod on the host-feeding and development

964 of Haemaphysalis flava nymphs (Acari: Ixodidae). Med. Entomol. Zool. 49, $965 \quad 235-238$.

966 Fujimoto, K., 1999. The host-feeding activity of Haemaphysalis flava females

967 observed under experimental conditions. Med. Entomol. Zool. 50, 57-59.

968 Fujimoto, K., 2001. A preliminary study on the termination of the behavioural

969 diapause of Ixodes persulcatus adults (Acari: Ixodidae). Med. Entomol. Zool.

$970 \quad 52,73-75$. 
971 Fujimoto, K., 2002. Effect of exposure to short-day photoperiods on the host

972 feeding activity of Ixodes persulcatus Schulze nymphs (Acari: Ixodidae)

973 reared in a long-day photoperiod before and after molting. Med. Entomol.

$974 \quad$ Zool. 53, 187-189.

975 Fujimoto, K., 2003. Preliminary studies on the termination of behavioral diapause

976 of Ixodes persulcatus Schulze adults (Acari: Ixodidae): Effects of the

977 exposure to a medium-day photoperiod. Med. Entomol. Zool. 54, 305-307.

978 Furman, D.P., Loomis, E.C. 1984. The ticks of California (Acari: Ixodida). Bull.

979 Calif. Insect Surv. 25, 1-239.

980 Gardiner, W.P., Gray, J.S., 1986. A computer simulation of the effects of specific 981 environmental factors on the development of the sheep tick Ixodes ricinus L.

982 Vet. Parasitol. 19, 133-144.

983 Gatewood, A.G., Liebman, K.A., Vourc'h, G., Bunikis, J., Hamer, S.A., Cortinas,

984 R., Melton, F., Cislo, P., Kitron, U., Tsao, J., Barbour, A.G., Fish, D., Diuk-

985 Wasser, M.A., 2009. Climate and tick seasonality are predictors of Borrelia

986 burgdorferi genotype distribution. Appl. Environ. Microbiol. 75, 2476-2483.

987 Gilbert, L., Aungier, J., Tomkins, J.L., 2014. Climate of origin affects tick (Ixodes

988 ricinus) host-seeking behavior in response to temperature: implications for

989 resilience to climate change? Ecol. Evol. 4, 1186-1198.

990 Goddard, J., 1992. Ecological studies of adult Ixodes scapularis in central

991 Mississippi: questing activity in relation to time of year, vegetation type, and

992 meteorologic conditions. J. Med. Entomol. 29, 501-506.

993 Gray, J.S., 1981. The fecundity of Ixodes ricinus L. and the mortality of 
994 developmental stages under field conditions. Bull. Entomol. Res. 71, 533$995 \quad 542$.

996 Gray, J.S., 1982. The development and questing activity of Ixodes ricinus L. 997 under field conditions in Ireland. Bull. Entomol. Res. 72, 263-270.

998 Gray, J.S., 1984. Studies on the dynamics of active populations of the sheep tick, 999 Ixodes ricinus L. in Co. Wicklow, Ireland. Acarologia 25, 167-178.

1000 Gray, J.S., 1987. Mating and behavioural diapause in Ixodes ricinus L. Exp. Appl. 1001 Acarol. 3, 61-71.

1002 Gray, J.S., 1991. The development and seasonal activity of the tick, Ixodes 1003 ricinus: a vector of Lyme borreliosis. Rev. Med. Vet. Entomol. 79, 323-333. 1004 Gray, J.S., 1998. The ecology of ticks transmitting Lyme borreliosis. Exp. Appl. 1005 Acarol. 22, 249-258.

1006 Gray, J.S., 2008. Ixodes ricinus seasonal activity: implications of global warming 1007 indicated by revisiting tick and weather data. Int. J. Med. Microbiol. 298, 1008 supplement 1, 19-24.

1009 Hamer, S.A., Hickling, G.J., Sidge, J.L., Walker, E.D., Tsao, J.I., 2012.

1010 Synchronous phenology of juvenile Ixodes scapularis, vertebrate host 1011 relationships, and associated patterns of Borrelia burgdorferi ribotypes in the 1012 midwestern United States.Ticks Tick Borne Dis. 3, 65-74.

1013 Hancock, P.A., Brackley, R., Palmer, S.C., 2011. Modelling the effect of 1014 temperature variation on the seasonal dynamics of Ixodes ricinus tick 1015 populations. Int. J. Parasitol. 41, 513-522.

1016 Harris, R.L., 1959. Biology of the black-legged tick. J. Kans. Entomol. Soc. 32, 
$1017 \quad 61-68$.

1018 Hubálek, Z., Halouzka, J., Juricová, Z., 2003. Host-seeking activity of ixodid ticks 1019 in relation to weather variables. J. Vector Ecol. 28, 159-165.

1020 Kachanko, N.I., 1978. [Development of ixodid ticks in the northern limits of their 1021 geographic range in Amur Province] (Russian). Parazitologiia 20, 218-225. 1022 Kahl, O., 1989. [Investigations on the water balance of ticks (Acari, Ixodoidea) in 1023 the course of their postembryonic development with special reference to 1024 active water vapour uptake in the engorged phases] (German). Dissertation, 1025 Free University of Berlin, Germany, 356 pp.

1026 Kahl, O.,1991. Water management of the non-parasitic phases of Ixodes ricinus 1027 in the course of its post-embryonic development. In: Dusábek, F., Bukva, V. 1028 (Eds.), Modern Acarology, Academia, Prague and SPB Academic Publishing 1029 bv, The Hague, Vol. 2, pp. 371-374.

1030 Kahl, O., Knülle, W., 1988a. [Seasonal and diurnal activity pattern of Ixodes 1031 ricinus (Acari, Ixodidae) and its infection with Lyme spirochetes and tick-borne 1032 encephalitis (TBE) virus in Berlin (West)] (German). Mitt. Dtsch. Ges. Allg. 1033 Angew. Entomol. 6, 223-225.

1034 Kahl, O., Knülle, W., 1988b. Water vapour uptake from subsaturated atmosphere 1035 by engorged immature ixodid ticks. Exp. Appl. Acarol. 4, 73-88.

1036 Kain, D.E., Sperling, F.A.H., Lane, R.S., 1997. Population genetic structure of 1037 Ixodes pacificus (Acari: Ixodidae) using allozymes. J. Med. Entomol, 34, 4411038450.

1039 Kheisin, E.M., Pavlovskaya, O., Malakhova, R.P., Rybak, V.F., 1955. [Duration of 
1040 the developmental cycle of Ixodes persulcatus under natural conditions of the 1041 Karelo-Finnish SSR] (Russian). Proceedings of the Karelo-Finnish University, $10426,102-123$.

1043 Kiewra, D., Kryza, M., Szymanowski, M., 2014. Influence of selected 1044 meteorological variables on the questing activity of Ixodes ricinus ticks in 1045 Lower Silesia, SW Poland. J. Vector Ecol. 39, 138-145.

1046 Kollars, T.M., Oliver, J.H., Kollars, P.G., Durden, L.A., 1999. Seasonal activity 1047 and host associations of Ixodes scapularis (Acari: Ixodidae) in southeastern 1048 Missouri. J. Med. Entomol. 36, 720-726.

1049 Korenberg, E.I., 2000. Seasonal population dynamics of Ixodes ticks and tick1050 borne encephalitis virus. Exp. Appl. Acarol. 24, 665-681.

1051 Korotkov, Y.S., 2008. [Variability of the life cycle duration in the taiga tick from 1052 mixed coniferous-broad-leaved forests of the Udmurt Republic] (Russian). 1053 Parazitologiia 42, 264-270.

1054 Korotkov, Y.S., 2009. [Ecology of the taiga ticks (Ixodes persulcatus Schulze, 1055 1930) under conditions of climate change in Eurasia] (Russian). Abstract of a 1056 dissertation for the degree of Dr. Biol. Sci. Moscow, Chumakov Institute of 1057 Poliomyelitis \& Viral Encephalitides. 46 pp.

1058 Korotkov, Y.S., Kislenko, G.S., 1991. [The morphogenetic diapause of the taiga 1059 tick and the methods for its quantitative assessment in a field experiment] 1060 (Russian). Parazitologiia (St. Petersburg) 25, 494-503.

1061 Kostál, V., 2006. Eco-physiological phases of insect diapause. J. Insect Physiol. $106252,113-127$. 
1063 Lane, R.S., Stubbs, H.A., 1990. Host-seeking behavior of adult Ixodes pacificus

1064 (Acari: Ixodidae) as determined by flagging vegetation. J. Med. Entomol. 27, $1065 \quad 282-287$.

1066 Lane, R.S., Fedorova, N., Kleinjan, J.E., Maxwell, M., 2013. Eco-epidemiological

1067 factors contributing to the low risk of human exposure to ixodid tick-borne

1068 borreliae in southern California, USA. Ticks Tick Borne Dis. 4, 377-385.

1069 Lane, R.S., Mun, J., Peribáñez, M.A., Stubbs, H.A., 2007. Host-seeking behavior

1070 of Ixodes pacificus (Acari: Ixodidae) nymphs in relation to environmental

1071 parameters in dense-woodland and woodland-grass habitats. J. Vector Ecol.

$1072 \quad 32,342-357$.

1073 Levin, M.L., 1984. [Characteristics of the spatial distribution of unfed taiga tick

1074 nymphs] (Russian). In: Kucheruk, V.V. (Ed.), Proceedings of XI All-Union

1075 Conference on Natural Focality of Diseases. Tyumen, USSR. pp. 94-96.

1076 Levin, M.L., 1987. [Biology of the unfed larvae of the taiga tick Ixodes persulcatus

1077 under natural conditions] (Russian). Zool. Zh. 66, 348-359.

1078 Lindsay, L.R., Barker, I.K., Surgeoner, G.A., McEwen, S.A., Gillespie, T.J.,

1079 Addison, E.M., 1998. Survival and development of the different life stages of

1080 Ixodes scapularis (Acari: Ixodidae) held within four habitats on Long Point,

1081 Ontario, Canada. J. Med. Entomol. 35, 189-199.

1082 MacDonald, A.J., Briggs, C.J., 2016. Truncated seasonal activity patterns of the 1083 western blacklegged tick (Ixodes pacificus) in central and southern California.

1084 Ticks Tick Borne Dis. 7, 234-242.

1085 MacLeod, J., 1935. Ixodes ricinus in relation to its physical environment. II. The 
1086 factors governing survival and activity. Parasitology $27,123-144$.

1087 Mackay, A., Foil, L., 2005. Seasonal and geographical distribution of adult Ixodes

1088 scapularis say (Acari: Ixodidae) in Louisiana. J. Vector. Ecol. 30, 168-170.

1089 Madder, M., Speybroeck, N., Brandt, J., Berkvens, D., 1999. Diapause induction

1090 in adults of three Rhipicephalus appendiculatus stocks. Exp. Appl. Acarol.

$1091 \quad 23,961-968$.

1092 McEnroe, W.D., 1985. Adaptions in the life cycle of Dermacentor variabilis (Say)

1093 and Ixodes dammini (Spielman, Clifford, Piesman, and Corwin) marginal

1094 populations (Acari: Ixodidae). Exp. Appl. Acarol. 1, 179-184.

1095 Mejlon, H.A., 1997. Diel activity of Ixodes ricinus (Acari:Ixodidae) at two locations 1096 near Stockholm, Sweden. Exp. Appl. Acarol. 21, 247-255.

1097 Milne, A., 1945. The ecology of the sheep tick, Ixodes ricinus L. The seasonal 1098 activity in Britain with particular reference to Northern England. Parasitology $109936,141-152$.

1100 Ogden, N.H., Lindsay, L.R., Beauchamp, G., Charron, D., Maarouf, A., 1101 O'Callaghan, C.J., Waltner-Toews, D., Barker, I.K., 2004. Investigation of 1102 relationships between temperature and developmental rates of tick Ixodes 1103 scapularis (Acari: Ixodidae) in the laboratory and field. J. Med. Entomol. 41, $1104 \quad 622-633$.

1105 Ogden, N.H., Bigras-Poulin, M., O'Callaghan, C.J., Barker, I.K., Lindsay, L.R., 1106 Maarouf, A., Smoyer-Tomic, K.E., Waltner-Toews, D., Charron, D., 2005. A 1107 dynamic population model to investigate effects of climate on geographic 1108 range and seasonality of the tick Ixodes scapularis. Int. J. Parasitol. 35, 375- 
839.

1110 Padgett, K.A., Lane, R.S., 2001. Life cycle of Ixodes pacificus (Acari: Ixodidae):

1111 timing of developmental processes under field and laboratory conditions. J.

1112 Med. Entomol. 38, 684-693.

1113 Peavey, C.A., Lane, R.S., 1996. Field and laboratory studies on the timing of

1114 oviposition and hatching of the western black-legged tick, Ixodes pacificus

1115 (Acari: Ixodidae). Exp. Appl. Acarol. 20, 695-711.

1116 Pegram, R.G., Banda, D.S., 1990. Ecology and phenology of cattle ticks in

1117 Zambia: development and survival of free-living stages. Exp. Appl. Acarol. 8, 1118 291-301.

1119 Perret, J.L., Guigoz, E., Rais, O., Gern, L., 2000. Influence of saturation deficit 1120 and temperature on Ixodes ricinus tick questing activity in a Lyme borreliosis1121 endemic area (Switzerland). Parasitol. Res. 86, 554-557.

1122 Qiu, W.G., Dykhuizen, D.E., Acosta, M.S., Luft, B.J., 2002. Geographic uniformity

1123 of the Lyme disease spirochete (Borrelia burgdorferi) and its shared history

1124 with tick vector (Ixodes scapularis) in the Northeastern United States.

1125 Genetics 160, 833-849.

1126 Randolph, S.E., 2004. Tick ecology: processes and patterns behind the 1127 epidemiological risk posed by ixodid ticks as vectors. Parasitology 129, S371128 S66.

1129 Randolph, S.E., 2013. Is expert opinion enough? A critical assessment of the 1130 evidence for potential impacts of climate change on tick-borne diseases. 1131 Anim. Health. Res. Rev. 14, 133-137. 
1132 Randolph, S.E., Green, R.M., Hoodless, A.N., Peacey, M.F., 2002. An empirical

1133 quantitative framework for the seasonal population dynamics of the tick

1134 Ixodes ricinus. Int. J. Parasitol. 32, 979-989.

1135 Salkeld, D.J., Castro, M.B., Bonilla, D., Kjemtrup, A., Kramer, V.L., Lane, R.S.,

1136 Padgett, K.A., 2014. Seasonal activity patterns of the western black-legged

1137 tick, Ixodes pacificus, in relation to onset of human Lyme disease in

1138 northwestern California. Ticks Tick Borne Dis. 5, 790-796.

1139 Sannasi, A., Subramoniam, T., 1972. Hormonal rupture of larval diapause in the 1140 tick Rhipicephalus sanguineus (Lat.). Experientia 28, 666-667.

1141 Shashina, N.I., 1985. Total duration of life cycle (Russian). pp. 275-277. In:

1142 Filippova, N.A. (Ed.), Taiga Tick Ixodes persulcatus Schulze (Acarina,

1143 Ixodidae): Morphology, Systematics, Ecology, and Medical Significance.

$1144 \quad$ Nauka, Leningrad.

1145 Smith, C.N., Cole, M.M., 1941. Effect of length of day on the activity and

1146 hibernation of the American dog tick, Dermacentor variabilis. Ann. Ent. Soc.

$1147 \quad$ Am. 34, 426-431.

1148 Spielman, A., Wilson, M.L., Levine, J.F., Piesman, J., 1985. Ecology of Ixodes

1149 dammini-borne human babesiosis and Lyme disease. Annu. Rev.

$1150 \quad$ Entomol.30, 439-460.

1151 Stanek, G., Wormser, G.P., Gray, J., Strle, F., 2012. Lyme borreliosis. Lancet $1152 \quad 379,461-473$.

1153 Tauber, M.J., Tauber, C.A., Masaki, S., 1986. Seasonal adaptations of insects. $1154 \quad$ New York; Oxford University Press. 411 pp. 
1155 Vahedi-Noori, N., Rahbari, S., Bokaei, S., 2012. The seasonal activity of Ixodes

1156 ricinus tick in Amol, Mazandaran Province, Northern Iran. J. Arthropod Borne

1157 Dis. 6, 129-135.

1158 Vail, S.G., Smith, G., 1998. Air temperature and relative humidity effects on

1159 behavioral activity of blacklegged tick (Acari: Ixodidae) nymphs in New

1160 Jersey. J. Med. Entomol. 35, 1025-1028.

1161 Walker, A.R., 2001. Age structure of a population of Ixodes ricinus (Acari:

1162 Ixodidae) in relation to its seasonal questing. Bull. Entomol. Res. 91, 69-78.

1163 Westrom, D.R., Lane, R.S., Anderson, J.R., 1985. Ixodes pacificus (Acari:

1164 Ixodidae): Population dynamics and distribution on Columbian blacktailed

1165 deer (Odocoileus hemionus columbianus). J. Med. Entomol. 12, 507-511.

1166 Wilkinson, P.R., 1968. Phenology, behavior, and host-relations of Dermacentor

1167 andersoni Stiles in outdoor "rodentaria" and in nature. Can. J. Zool. 46, 677$1168 \quad 689$.

1169 Yousfi-Monod, R., Aeschlimann, A.,1986. [Studies on ticks (Acarina, Ixodidae),

1170 parasites of cattle in West Algeria. I. Systematic survey and seasonal activity]

1171 (French). Ann. Parasitol. Hum. Comp. 61, 341-358.

1172 Yuval, B., Spielman, A., 1990. Duration and regulation of the developmental

1173 cycle of Ixodes dammini (Acari: Ixodidae). J. Med. Entomol. 27, 196-201.

1174 Zemskaya, A.A., 1984. Seasonal activity of adult ticks Ixodes persulcatus P. Sch.

1175 in the eastern part of the Russian Plain. Folia Parasitol. (Praha) 31, 260-276.

1176 Zhmaeva, Z.M., 1969. [About development of Ixodes persulcatus P. Sch. in

1177 European south-taiga forests] (Russian). Tick-borne encephalitis in Udmurtia 
1178 and the surrounding areas. In: Tick-Borne Encephalitis in Udmurtia and

1179 Adjacent Regions. Izhevsk, pp. 118-141. 
Fig. 1. Ixodes ricinus species-complex life cycle. The four species considered in this review (I. pacificus, I. persulcatus, I. ricinus and I. scapularis) have similar life cycles and utilize the same range of hosts. Diapause can delay host-seeking following the moult, or delay development of one stage to the next.

Fig. 2. Stylized Ixodes ricinus questing activity in deciduous woodland (central and western Europe) in an area where appreciable autumn activity occurs, depicting the relationships of seasonal larval (L), nymphal (N) and adult (A) peaks, and the critical diapause period $(\boldsymbol{\Delta})$.

A. Seasonal activity peaks of the three active stages (larva, nymph, adult) as observed within one year.

B. Chronological representation of diapause regulation of seasonal activity, showing the origin of the activity peaks of the different stages

\# Although this diagram may appear to illustrate a 3-year cycle, in reality the flexibility of $I$. ricinus development and the influence of diapause means that 2-6 years may be taken to complete the life cycle.

a Overwintering as unfed stages or non-diapausing eggs, most nymphs and adults in Behavioural Diapause.

b Overwintering as fed stages or eggs in Developmental Diapause.

In this scenario the majority of ticks in a particular category, $a$ or $b$, appear as the next life cycle stage in the same season a year later, regulated by developmental or behavioural diapause. However, considerable variation on this basic pattern can occur.

c Derived from the previous life stage that fed in spring/summer of the same year.

....... Critical diapause period (indicating the approximate photoperiod threshold after which date the majority of ticks enter diapause).

* The precise timing of the critical diapause period for adults is uncertain. This diapause manifests as delayed embryogenesis in the egg, but the induction stimulus is perceived by the questing mother tick. 
Table 1. Light and temperature conditions for laboratory rearing of Ixodes pacificus, I. persulcatus, I. ricinus and I. scapularis

\begin{tabular}{|c|c|c|c|c|}
\hline $\begin{array}{l}\text { Category } \\
\text { (no. of labs) }\end{array}$ & Tick species & Feeding & Development & Storage \\
\hline $\mathrm{A}(8)$ & $\begin{array}{l}\text { I. pacificus } \\
\text { I. ricinus } \\
\text { I. scapularis }\end{array}$ & ( LD, $\mathrm{M}-\mathrm{H} \mathrm{T}^{\circ} \mathrm{C}$ & LD, M-H T ${ }^{\circ} \mathrm{C}$ & $\begin{array}{l}\mathrm{LD} \text { (or dark for longterm- } \\
\text { one lab), } \mathrm{M}-\mathrm{H} \mathrm{T}^{\circ} \mathrm{C}\end{array}$ \\
\hline $\mathrm{B}(3)$ & I. ricinus & $\mathrm{LD}, \mathrm{M}-\mathrm{H} \mathrm{T}^{\circ} \mathrm{C}$ & $\mathrm{LD}, \mathrm{M}-\mathrm{H} \mathrm{T}^{\circ} \mathrm{C}$ & $\mathrm{SD} /$ dark, $\mathrm{L} \mathrm{T}^{\circ} \mathrm{C}$ \\
\hline $\mathrm{C}(2)$ & I. ricinus & $\mathrm{LD}, \mathrm{M} \mathrm{T}^{\circ} \mathrm{C}$ & $\mathrm{LD}, \mathrm{M} \mathrm{T}^{\circ} \mathrm{C}$ & $\mathrm{LD}, \mathrm{M} \mathrm{T}^{\circ} \mathrm{C}$ \\
\hline $\mathrm{D}(1)$ & $\begin{array}{l}\text { I. persulcatus } \\
\text { I. ricinus } \\
\text { I. scapularis }\end{array}$ & $\begin{array}{l}\mathrm{LD}, \mathrm{M} \mathrm{T}^{\circ} \mathrm{C} \text {; } \\
\text { adults in dark }\end{array}$ & $\mathrm{LD}, \mathrm{M} \mathrm{T}^{\circ} \mathrm{C}$ & $\begin{array}{l}\text { nymphs/adults dark, } \mathrm{L} \mathrm{T}^{\circ} \mathrm{C} \text {; } \\
\text { larvae } \mathrm{LD}, \mathrm{M} \mathrm{T} \mathrm{T}^{\circ} \mathrm{C}\end{array}$ \\
\hline $\mathrm{E}(1)$ & I. ricinus & $\mathrm{LD}, \mathrm{M} \mathrm{T}^{\circ} \mathrm{C}$ & $\mathrm{SD}, \mathrm{M} \mathrm{T}^{\circ} \mathrm{C}$ & $\mathrm{SD}, \mathrm{M} \mathrm{T}^{\circ} \mathrm{C}$ or dark, $\mathrm{L} \mathrm{T}^{\circ} \mathrm{C}$ \\
\hline $\mathrm{F}(1)$ & $\begin{array}{l}\text { I. pacificus } \\
\text { I. persulcatus } \\
\text { I. ricinus } \\
\text { I. scapularis }\end{array}$ & $\mathrm{SD}, \mathrm{M} \mathrm{T}^{\circ} \mathrm{C}$ & $\mathrm{LD}, \mathrm{H} \mathrm{T}^{\circ} \mathrm{C}$ & $\begin{array}{l}\text { nymphs/adults dark, } \mathrm{L} \mathrm{T}^{\circ} \mathrm{C} \text {; } \\
\text { larvae } \mathrm{LD}, \mathrm{H} \mathrm{T}^{\circ} \mathrm{C}\end{array}$ \\
\hline G (1) & I. persulcatus & $\mathrm{SD}, \mathrm{M} \mathrm{T}^{\circ} \mathrm{C}$ & $\mathrm{SD}, \mathrm{M} \mathrm{T}^{\circ} \mathrm{C}$ & dark, $\mathrm{L} \mathrm{T}^{\circ} \mathrm{C}$ \\
\hline $\mathrm{H}(1)$ & I. ricinus & $\mathrm{SD}, \mathrm{H} \mathrm{T}^{\circ} \mathrm{C}$ & $\mathrm{SD}, \mathrm{H} \mathrm{T}^{\circ} \mathrm{C}$ & $\mathrm{SD}, \mathrm{H} \mathrm{T}^{\circ} \mathrm{C}$ \\
\hline
\end{tabular}

Long-day $(\mathrm{LD})=>12$ hours light per 24-hr period; Short-day $(\mathrm{SD})=<12$ hours light $/ 24$-hr period

High $(\mathrm{H})$ temperature $\left(\mathrm{T}^{\circ} \mathrm{C}\right)=>20^{\circ} \mathrm{C}$; medium $(\mathrm{M})$ temperature $=10-20^{\circ} \mathrm{C}$; low $(\mathrm{L})$ temperature $=4-9^{\circ} \mathrm{C}$

Table 2. Occurrence of diapause in Ixodes pacificus, I. persulcatus, I. ricinus and I. scapularis

\begin{tabular}{|l|c|c|}
\hline Tick species & Developmental diapause & Behavioural diapause \\
\hline I. pacificus & unknown & L, N \\
\hline I. persulcatus & L, N & N, A \\
\hline I. ricinus & E, L, N & N, A \\
\hline I. scapularis & N, Pre-ov & $\mathrm{N}$ \\
\hline
\end{tabular}

$\mathrm{E}=$ egg, $\mathrm{L}=$ larva, $\mathrm{N}=$ nymph, $\mathrm{A}=$ adult, Pre-ov = pre-ovipositional 


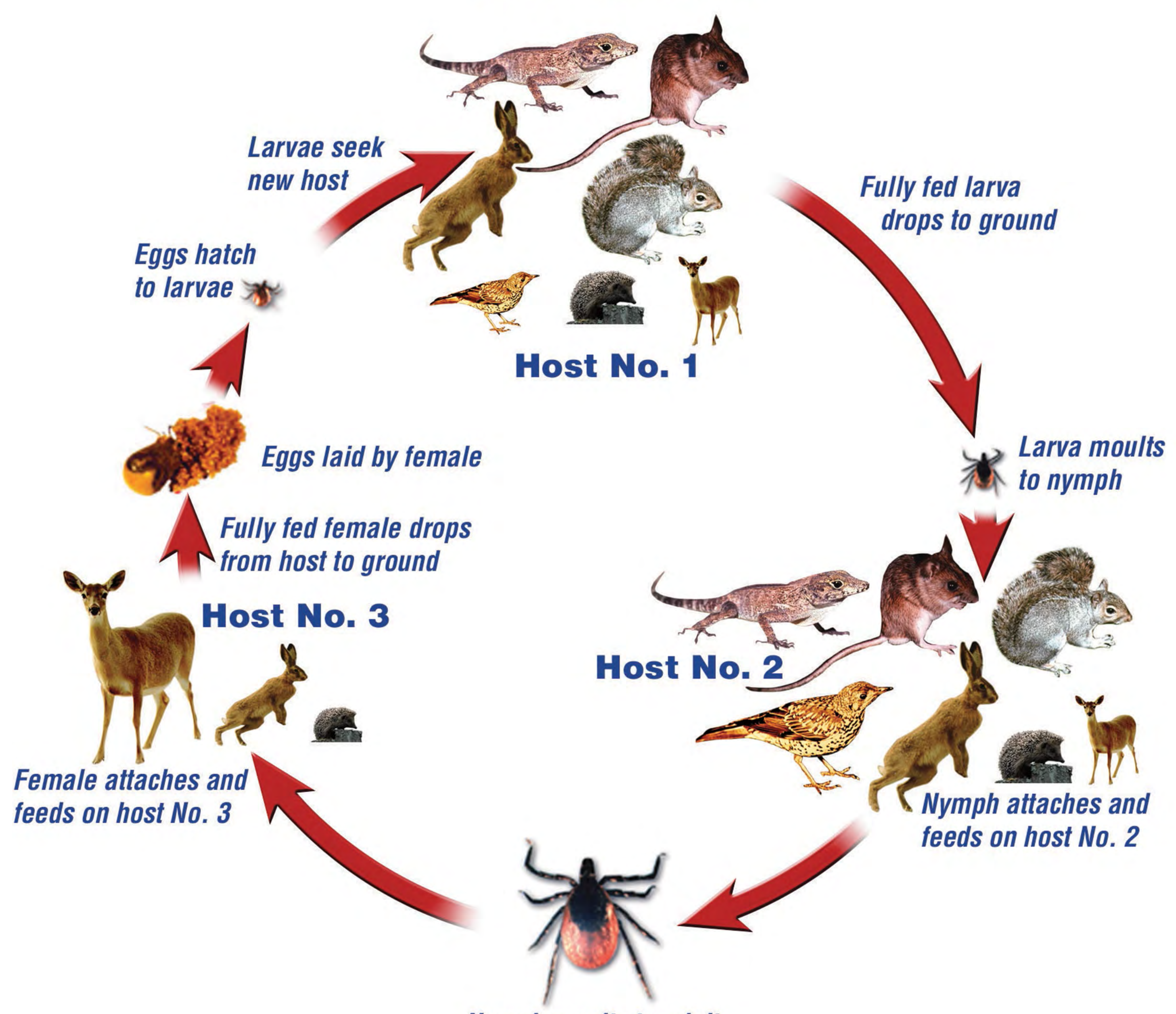


$\mathrm{B}^{*}$

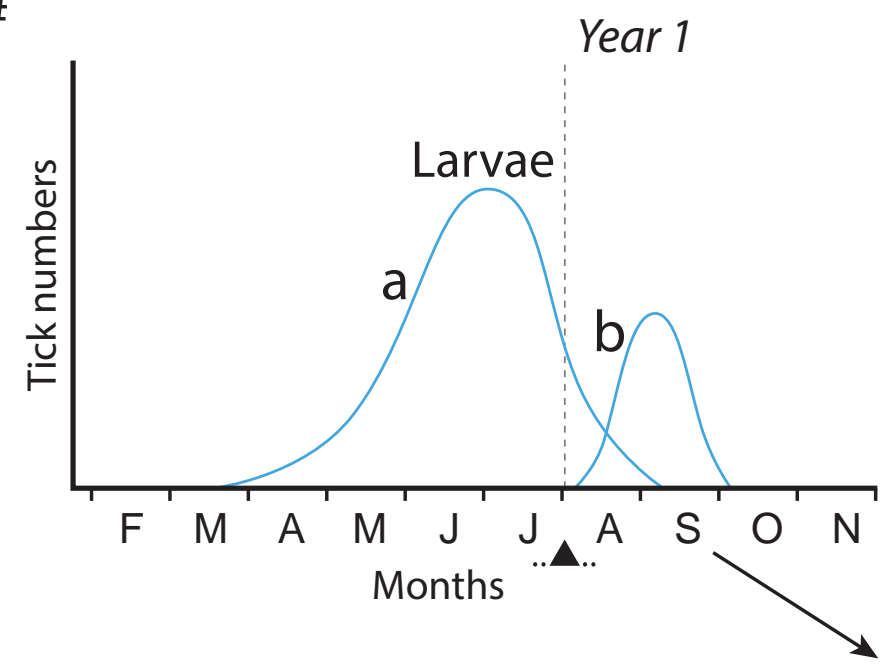

Figure 2

A

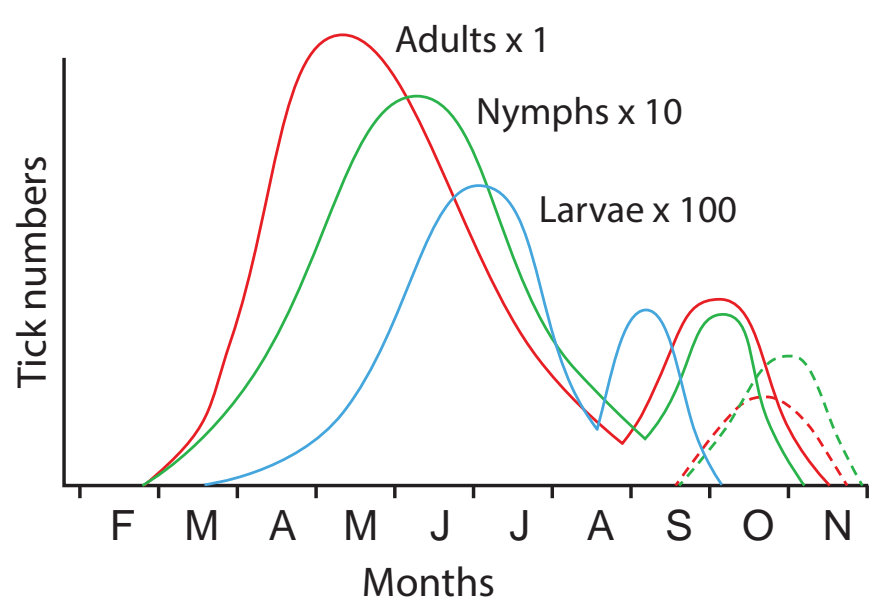

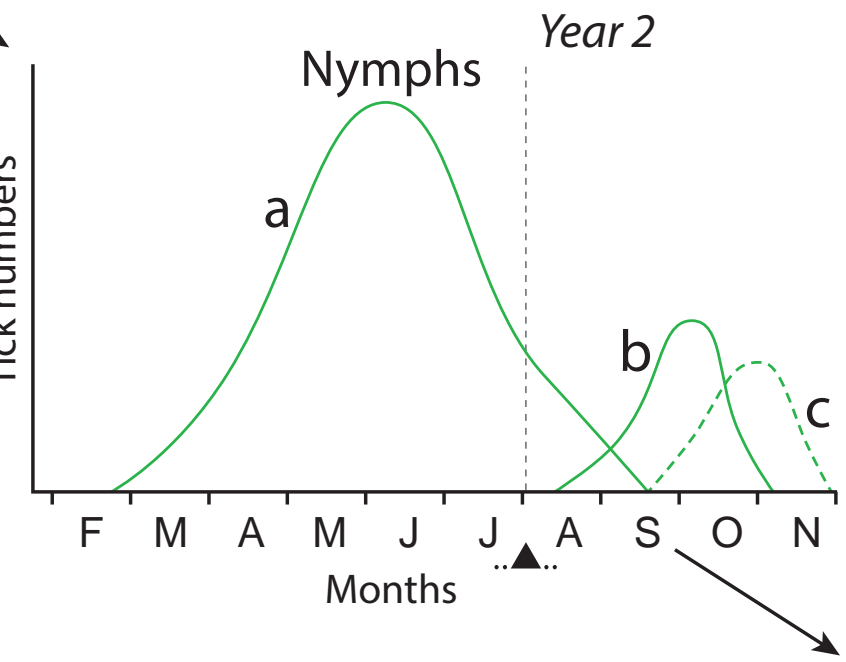

\section{Adults Year 3}

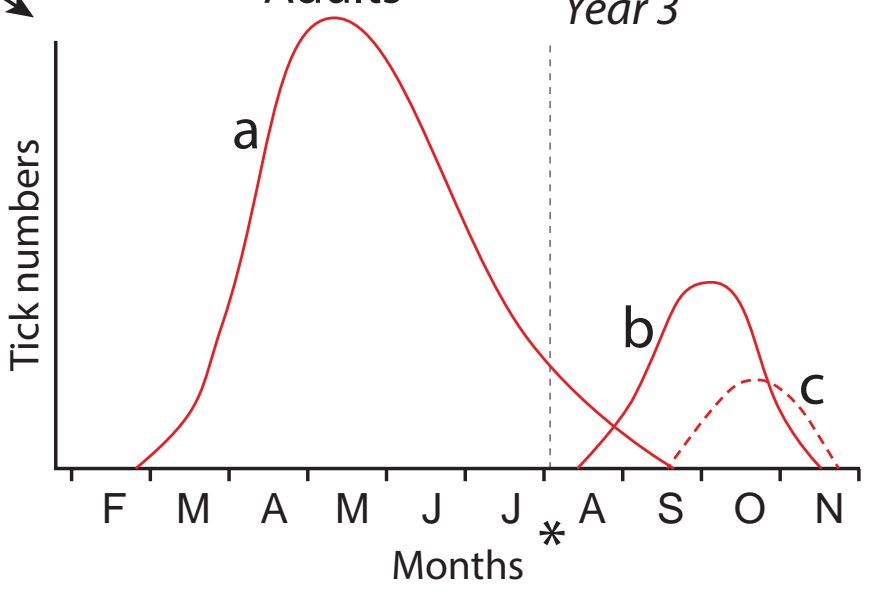

